\title{
Implementing pricing strategies
}

\author{
Andreas Hinterhuber ${ }^{1}$
}

Published online: 13 November 2017

(C) Macmillan Publishers Ltd., part of Springer Nature 2017

\begin{abstract}
This Editorial presents the papers submitted to the special issue "Implementing pricing strategies." The papers discuss a variety of topics, notably the implementation of revenue management and pricing in Disney, the implementation of value-based selling and pricing in industrial companies, the design of effective sales force compensation systems to facilitate the implementation of value-based pricing and issues related to price presentation. The papers in this special issue suggest that the ability to implement pricing strategies is a watermark separating high-performing from merely average companies. We need more research on this important topic.
\end{abstract}

Keywords Implementation · Pricing · Value-based pricing $\cdot$ Performance $\cdot$ Organization $\cdot$ Value quantification $\cdot$ Value-based selling

Implementation is a tricky part in the strategy process. Strategy development requires creativity, analytical rigor, and an ability to master the internal political competition for scarce resources, but it takes place in a well-defined environment. Fast forward to strategy implementation: competitors that stubbornly fail to behave according to assumptions, new entrants, internal resistance, new opportunities, changing customer preferences, leadership changes, regulatory interventions, or market growth rates that change unexpectedly are some of the intervening variables between the strategy originally developed and the strategy actually implemented. On the continuum between top-down and bottom-up/emerging approaches to strategy

Andreas Hinterhuber

andreas@hinterhuber.com

Hinterhuber \& Partners, Falkstrasse 16, Innsbruck, Austria implementation, there are numerous theoretical modelsthe 8-step change model by Kotter (1995), the Change Acceleration Process by General Electric (Ulrich et al. 2002), the influence model by McKinsey \& Company (Keller and Price 2011), the switch model by the Heath brothers (Heath and Heath 2010)_all waiting to be empirically tested: Illuminating this fascinating process by analyzing how specifically pricing strategies are implemented was one objective of this call for papers "Implementing pricing strategies." We made modest progress, if at all.

This special issue consists of four papers plus one interview, selected after a competitive review process from eleven submissions after two rounds of review.

In the interview "Elevating the cost of doing nothingAn interview with Mark Shafer," Andreas Hinterhuber and Evandro Pollono discuss with Mark Shafer the implementation of revenue management and pricing at Disney from the perspective of the company's Senior Vice President of Revenue and Profit Management. Highlights of this interview that is bound to inspire research and practice include the comment that "the cost of doing nothing is not zero," suggesting that elevating the cost of inaction can overcome internal resistance to change and may thus be an important instrument for articulating the need for change. The interview also sheds light on the characteristics at the level of individual decision makers that facilitate the implementation of pricing and revenue management and reminds us of the ever present, frequently invisible biases in this process. Finally, the interview illuminates how Mark Shafer was able to instill a sense of passion for data and analytics in a company that is a legend in the entertainment industry.

The paper "Designing salesforce compensation programs to improve pricing execution" by Stephan Liozu examines 
the role of sales force incentive systems in the implementation of value-based pricing strategies. The paper is based on interviews with 12 pricing managers in large B2B companies. Pricing strategies live and die in the hands of sales managers. Incentive systems play a role, probably even an important one, in pricing strategy implementation: The literature indicates that the implementation of value-based pricing requires a shift from purely volume-based sales force compensation approaches to approaches that also reward profitability or price realization (Nagle et al. 2011). This paper presents data on the mix between volume- and profitability-based sales force incentive systems that some large companies use to facilitate the implementation of valuebased pricing strategies. This paper suggests treating the introduction of new sales force incentive systems as a change management process, as opposed to a one-time event. This requires clarity on the envisioned future, planning, testing, a robust infrastructure (i.e., data), and top management support. This paper also points out that compensation is a highly sensitive topic. A sensible suggestion of this contribution is to allow sales managers to select the compensation approach of their liking during the transition period between the current and the new approach.

The paper "Nickel \& dime guests for amenities: exploring guests' perceptions of resort fees" by Seung Hyun Lee and Jaeyong Lee examines travel reactions to resort fees-essentially discretionary surcharges hotels impose to improve profitability-by analyzing comments on an independent booking platform. The data collection method is problematic: ideally, customer perceptions and booking behavior are analyzed in a control and in a test condition during comparable periods. Not surprisingly, this paper finds that travel reactions to resort fees are mostly negative. Open communication about this mostly hidden fee would probably reduce these reactions.

The paper "The importance of transparency signals in à la carte pricing" by Thomas Robbert and Stefan Roth analyze the influence of all-inclusive and a-la-carte pricing on student perceptions in a laboratory experiment. The paper finds that, with prices being equal, purchase intentions and perceptions of value are higher for all-inclusive pricing. The unfavorable perceptions of a-la-carte pricing seems to be driven largely by the impression that this pricing tactic is self-serving (i.e., designed to increase profits or mislead customers) and not customer serving (i.e., designed to increase customer satisfaction or transparency). Transparency in a-la-carte pricing seems to decrease negative perceptions.

The practice paper "Quantified value first, then price: Realizing the positive impact of a value pricing strategy" by Todd Snelgrove examines the critical factors that executives should focus on when implanting value-based selling and value-based pricing in B2B. This paper reminds readers that compensation is not the only factor. Snelgrove suggests that the two critical components to successfully implement value-based selling and pricing are (a) the ability to sell value and (b) the motivation to sell value. The organizational ability is the result of a shared conceptualization about what value is, a value selling process, tools, trainings, and experiential learning. The organizational motivation is the result of sales force compensation, a flexible offer structure enabling customers to select from multiple buying options, a culture built on delivering and communicating value to customers, and appropriate customer selection mechanisms targeting customers most receptive to the value offered. These nine building blocks of implementing value-based selling and pricing in B2B will resonate particularly with practitioners: among a myriad of potential factors, Snelgrove points out the few levers that truly matter when implementing value-based pricing. The paper quips about sales managers and athletes asking why performing athletes train continuously to improve performance, whereas few sales managers seem to understand the importance of continuously improving their value-based selling capabilities. This paper takes a nuanced view on pricing strategy implementation and points out that putting into sustained practice ideas such as value-based selling is, indeed, all but straightforward.

As the papers and the fascinating interview in this special issue suggest, the ability to implement pricing strategies separates in very clear and tangible terms highperforming from merely average companies. The implementation capability is a watermark. I trust the papers in this special issue contribute toward better managerial practice and further studies. We need both.

Andreas Hinterhuber

Hinterhuber \& Partners

Innsbruck, Austria

November 2017

\section{References}

Heath, C., and D. Heath. 2010. Switch: How to Change Things When Change Is Hard. New York: Random House, Inc.

Keller, S., and C. Price. 2011. Beyond Performance: How Great Organizations Build Ultimate Competitive Advantage. Hoboken: Wiley.

Kotter, J.P. 1995. Leading change: Why transformation efforts fail. Harvard Business Review 73(2): 59-67.

Nagle, T., J. Hogan, and J. Zale. 2011. The Strategy and Tactics of Pricing: A Guide to Growing More Profitably. Upper Saddle River: Prentice Hall.

Ulrich, D., S. Kerr, and R. Ashkenas. 2002. The Ge Work-Out: How to Implement Ge's Revolutionary Method for Busting Bureaucracy and Attacking Organizational Problems-Fast!. New York: McGraw-Hill. 